\title{
Optimizing the Lifespan of Perovskite Solar Cells with Polycarbonate Polymer Encapsulation
}

\author{
Asieh Nazari Mofrad ${ }^{\mathrm{a}}$, S.M. Bagher Ghorashia,", and Farhad Jahantigha,b,* \\ ${ }^{a}$ Atomic and Molecular Group, Faculty of Physics, University of Kashan, Kashan, Iran \\ ${ }^{b}$ Physics Department, Faculty of Basic Sciences, Khatam al Anbia University, Tehran, Iran
}

*Corresponding authors: mghorashi@kashanu.ac.ir and f.jahantigh@yahoo.com

Regular paper: Received: Jun. 18, 2021, Revised: Sep. 28, 2021, Accepted: Oct. 22, 2021, Available Online: Oct. 24, 2021, DOI: 10.52547/ijop.15.1.55

\begin{abstract}
One of the main challenges for perovskite solar cell (PSCs) structures is their high sensitivity to humidity and ambient temperature, which significantly lowers the lifespan of these devices. Low stability of this devices is considered one of the principal limitations to make them commercialized. To increase the stability of the solar cell is to encapsulate the solar cell. The encapsulation is to cover the device with a non-reactive material, which prevents the penetration of ambient moisture and increases the thermal stability of the cell. If the uncoated device is exposed to continuous incident light for several hours, its structure is damaged while encapsulated device has a longer duration time. Several methods have been proposed for encapsulating a perovskite solar cell. The principal strategy of these methods involves deposition of a thin layer of polycarbonate polymer on the perovskite solar cell structure, resulting in layers of the desired structure. After fabrication and encapsulation process, the order of the various layers are FTO / bl-TiO ${ }_{2} /{\mathrm{mp}-\mathrm{TiO}_{2}} /$ Perovskite $\left(\mathrm{CH} 3 \mathrm{NH}_{3} \mathrm{PbI}_{3}\right)$ / Spiro-OMETAD / Au / Polycarbonate Polymer. To increase the effective stability, the glass coating is placed on the polycarbonate polymer. After acquiring sufficient adhesion between the glass coating and the polymer layer on the structure of PSCs, UV epoxy is used to seal the whole structure. Having performed the encapsulation, the samples were exposed every day to $85 \%$ constant humidity and $85^{\circ} \mathrm{C}$ temperature for 10 hours and it was observed that the cell efficiency, under the mentioned conditions and after successive measurements, maintained to a high extent.
\end{abstract}

KEYWORDS: Photovoltaic, Perovskite solar cells, Encapsulation, Stability.

\section{I.INTRODUCTION}

Nowadays, because of the importance of new sources of energy, production of the materials which are able to generate electrical energy has come into focus. Sunlight is one of the natural resources that can be converted to electrical energy using photovoltaic cells. While inorganic lead halides have been studied since the nineteenth century [1]-[8]. Therefore, in order to provide the best performance of the mentioned devices, their lifespan should be increased with enclosing technology. The encapsulation process in OLED by $\mathrm{SiO} / \mathrm{Si} 3 \mathrm{~N} 4$ thin film addressing extends its lifespan from 2594 hours to 5694 hours [9]. [10]-[13] Adding rubidium and using deposited perovskite can increase moisture stability [14], [15] middle layers (interface) or protective layers are shown to reduce the penetration of moisture into the structure [16]-[19]. Bosch et al. demonstrated the first stability test that passed moisture and heat according to IEC61215: 2016 using ITO as a protective cap, and glass/ethylene vinyl acetate/butyl rubber as a package, although most of the stability tests performed at 1000 hours [20], [21], under uncontrolled conditions or non-standard conditions, these methods make it difficult to compare the stability of different structures. CIGS (Copper Indium Gallium Selenide) solar cells and organic light emitting diodes are also degraded when exposed to air and moisture in the environment [22], [23]. However, many common encapsulators such as ethylene vinyl acetate+butyl sealants for edges are used in commercial thin films of photovoltaic modules 
such as CIGS. In addition to the low cost of encapsulants, PSCs also require a lowtemperature encapsulation process whose processing temperature for all structures in which organic materials such as MA / FA are used must be below $200^{\circ} \mathrm{C}$ [24]. Therefore, a method is proposed to enclose the third generation perovskite solar cell and increase its lifespan.

\section{Experimental Procedure}

\section{A. Cell Fabrication and Enclosing Technology}

The Perovskite solar cell has attracted the attention of many researchers due to its rapid development, high efficiency, and relatively easy and cost-effective fabrication. The method of making a perovskite solar cell is very diverse, but among them one can consider a single method of construction. Accordingly, the fabrication of structure of Fig. 1 is described.

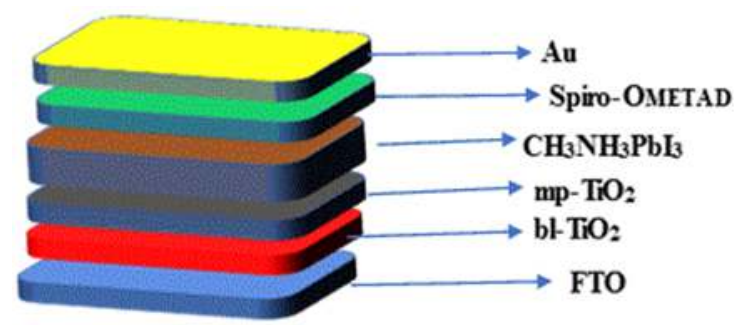

Fig. 1. Schematic illustration of structure of perovskite solar cell: $\mathrm{FTO} / \mathrm{bl}-\mathrm{TiO}_{2} / \mathrm{mp}-\mathrm{TiO}_{2} /$ Perovskite $\left(\mathrm{CH}_{3} \mathrm{NH}_{3} \mathrm{PbI}_{3}\right) /$ Spiro-OMETAD / Au.

First, some transparent FTO conductor must be peeled off the glass to prevent short circuit. For this purpose, consider an area of the surface to be peeled off and cover the rest of the surface in a way that the clear conductive oxide does not corrode the rest. For this purpose, zinc powder and two molar hydrochloric acid solution are used. After the peeling, it is time to wash the legs. This step is very important because the layers must be accumulated on a substrate free of any organic matter. The substrates should be washed with soap and water solution, then rinsed in deionized water, acetone, ethanol and isopropanol for $15 \mathrm{~min}$ in an ultrasonic bath. A UV-Ozone device is used to correct the surface. Then, to prevent the electrons recombination, the electron blocking layer $\left(\mathrm{bl}-\mathrm{TiO}_{2}\right)$ must be coated. Before applying the coating, part of the FTO must be covered to make the connection and place it in the circuit. Pour $5 \mathrm{cc}$ of dry ethanol into two clean glass containers, add some titanium isopropoxide solution (TTIP) to one of the glasses, and $2 \mathrm{M}$ hydrochloric acid solution to the other, and stir on a magnetic stirrer for $5 \mathrm{~min}$. Then the solution containing TTIP and Ethanol is added dropwise to a container containing two molar acid and it should be stirred for $5 \mathrm{~min}$ to get a fresh, clear, colorless and sediment-free solution. This solution is layered on the substrate using a spin coating machine [25]. After coating, the samples are usually dried at $120^{\circ} \mathrm{C}$ and annealed in an oven at $500^{\circ} \mathrm{C}$ for 30 min. For titanium oxide coating, a suspension of titanium oxide and ethanol paste in appropriate proportions must first be prepared and then allowed to obtain a fresh, white solution using a magnetic stirrer. The suspension is then deposited on the electron barrier layer by spin coating deposition, then the sample must be dried again at $120^{\circ} \mathrm{C}$. After that, to make porosity in the structure and correct it, it should be baked in a 500 degree oven in air for one hour. Sintering conditions of the glass frits plays an important role in the porosity of the glass frit before and after the bonding step. As mentioned before, glass frits are commonly available in the form of printable pastes. These pastes contain solvents and organic binders, which should be removed during the sintering process. Improper sintering condition results in the presence of pores in the sealing line. To prepare the perovskite layer, first pour $115 \mathrm{mg}$ of $\mathrm{PbI}_{2}$ into a container with a very accurate scale, then add $158 \mu$ of DMF solvent and $18 \mu \mathrm{l}$ of DMSO solvent and place it on a $70^{\circ} \mathrm{C}$ heater for one hour while stirring. After the solution has reached room temperature, add $80 \mathrm{mg}$ of MAI powder and stir for one extra hour until the final perovskite solution would be ready. Add $30 \mu \mathrm{l}$ of it on the sample with a micropipette and allow it to penetrate for a few seconds. Then turn on the spin coating device, which is pre-set so that first spins for 10 seconds at a speed of $1000 \mathrm{rpm}$, then for 20 seconds at a speed of $4000 \mathrm{rpm}$. While spinning, puff the amount of $200 \mu \mathrm{l}$ of chlorobenzene on the samples. Samples are then quickly placed on a $100^{\circ} \mathrm{C}$ heater for 15 
min to be backed in air, so that the solvents evaporate and what remains is perovskite. Two solutions must be prepared for the coating of the cavity transfer material using spiro-OMETAD in this structure. First, spiro-OMETAD powder, chlorobenzene and tetra-butyl peridin solvent are combined, then acetonitrile, which was added dropwise to Li-TFSI salt, is added to the solution containing spiro-OMETAD and the final solution is placed on a magnetic stirrer for $30 \mathrm{~min}$ at $60^{\circ} \mathrm{C}$. It is then coated on the perovskite layer by rotating the deposition method. To prepare the cathode, gold can be used due to its suitable work function with a purity of $99.99 \%$. The thermal evaporation method in vacuum is used for its layering. For this purpose, the samples are placed on a template and closed on a disk. Finally, in complete vacuum conditions, by applying current to a plant containing $\mathrm{Au}$, the $\mathrm{Au}$ can be evaporated and the Au electrode applied to the layer of the cavity transfer layer with the desired thickness.

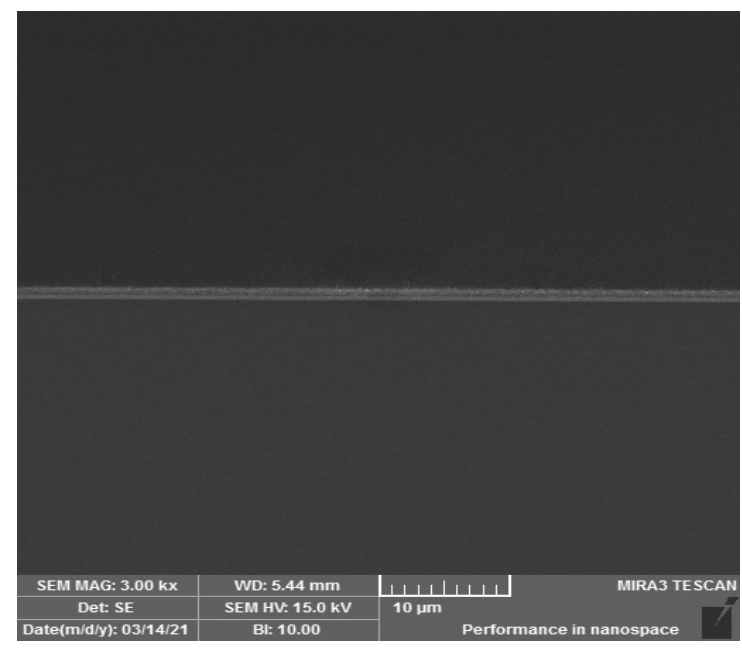

Fig. 2. Cross-sectional SEM images of perovskite solar cell.

Enclosure technology is an important part of third generation solar cell technology. Therefore, due to the importance of the lifespan of solar cells, enclosure technology has a special place that can be performed in different ways. Enclosures must have a high dielectric refraction that is consistent with the refractive index of the other layers and has a large volume of resistance. Also, these materials should be inexpensive, have dimensional stability, and easy to be coated. Therefore, after making PSCs and characterizing the current-voltage and calculating its efficiency, it is coated with different organic and inorganic materials to determine the best material with the mentioned properties. Figure 2 shows the cross-sectional of the cell. In this figure, separate layers, are quite distinct.

The UV-vis absorption spectrum of the polycarbonate is shown in Fig. 3. In the wavelength range of 400-700 $\mathrm{nm}$, polycarbonate is nearly transparent. In the range of $400-550 \mathrm{~nm}$, the absorption of this material is about 0.5 and from $550-800 \mathrm{~nm}$ is almost zero.

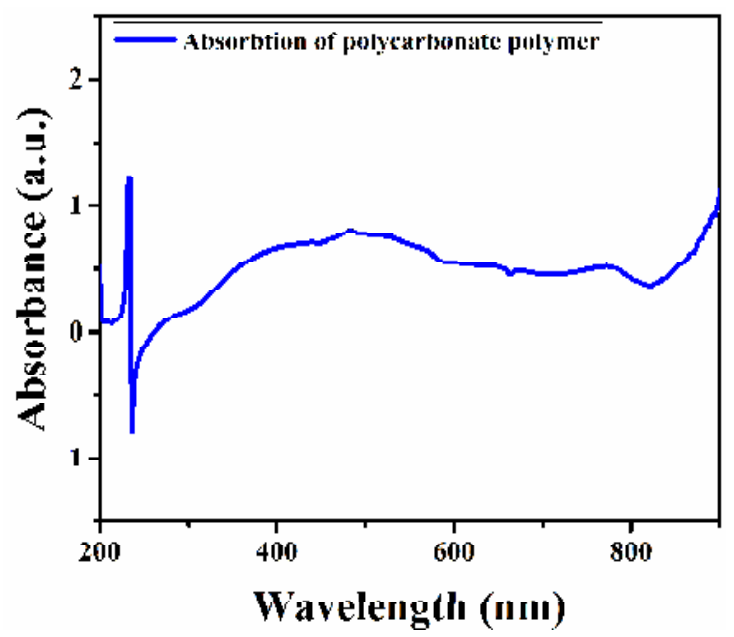

Fig. 3. UV-vis absorption spectrum of the polycarbonate.

To enclose the cell, the cell electrodes are first contacted with copper conductive adhesive tape, and the polycarbonate (PC) polymer, as the encapsulating material of PSCs that has all the necessary properties, is combined with dichloromethane solvent and is placed on a magnetic stirrer for 1 hour to create a uniform solution. Then, with a brush, a uniform level of this solution is placed on the cell, and the slide is placed on the cell and pressed to achieve the sufficient adhesion and strength after $20 \mathrm{~min}$. To seal the desired structure, the surrounding area is covered with UV epoxy and exposed to UV light for $4 \mathrm{~min}$ to get completely dried. Subsequently, at different time intervals, the samples are exposed to $85 \%$ humidity and $85^{\circ} \mathrm{C}$ to measure their efficiency every day. To create the mentioned conditions, the glove box has 
been used in such a way that after switching on the glove box, the heater fan is turned on and the moisture production cable is connected, then the humidity and temperature display is turned on and the perovskite solar cell is turned on. Place the reference and encapsulated cell in the glove box, record the time at which the temperature is $85^{\circ} \mathrm{C}$ and the humidity is $85 \%$ $\mathrm{RH}$, and the surface of the specimens is checked hourly to see whether the perovskite structure remains intact or destroyed. By measuring the $\mathrm{I}-\mathrm{V}$ of the structure and after reaching an approximate efficiency of $20 \%$ of the initial efficiency, the measurement process is completed. In this study, measurements were performed after applying moisture and heat in three consecutive directions. According to IEC61215, the cells were exposed to the desired conditions for 4 hours a day. In Fig. 4, an image of the cell before and after enclosure is shown.

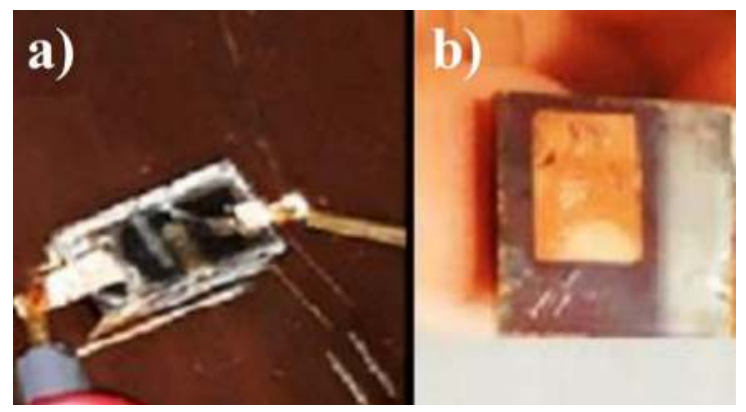

Fig. 4. (a) Perovskite solar cell before encapsulation, (b) solar cell enclosed with PC polymer and glass coating that continues to show stability under certain weather conditions and over time.

In the schematic of the structure of PSCs, a thin layer of encapsulating polymer is completely coated on the structure, which is the first stage of encapsulation, and after the coating is jellycoated, a glass slide is placed on the structure in the second stage and after fully attachment to the surface, in the last stage, UV glue is injected around the structure, with a syringe, to seal and the final capsulation, which is shown in Fig. 5 in the following steps.

Figure 6 also shows the current-voltage diagram of the cell, representing that PSCs have displayed good stability after encapsulation and a relatively long time. However, the efficiency of the unenclosed cell reaches zero after a short period of time, up to one hour, due to the mentioned conditions, and this is a good indication of the usefulness of the enclosing process.
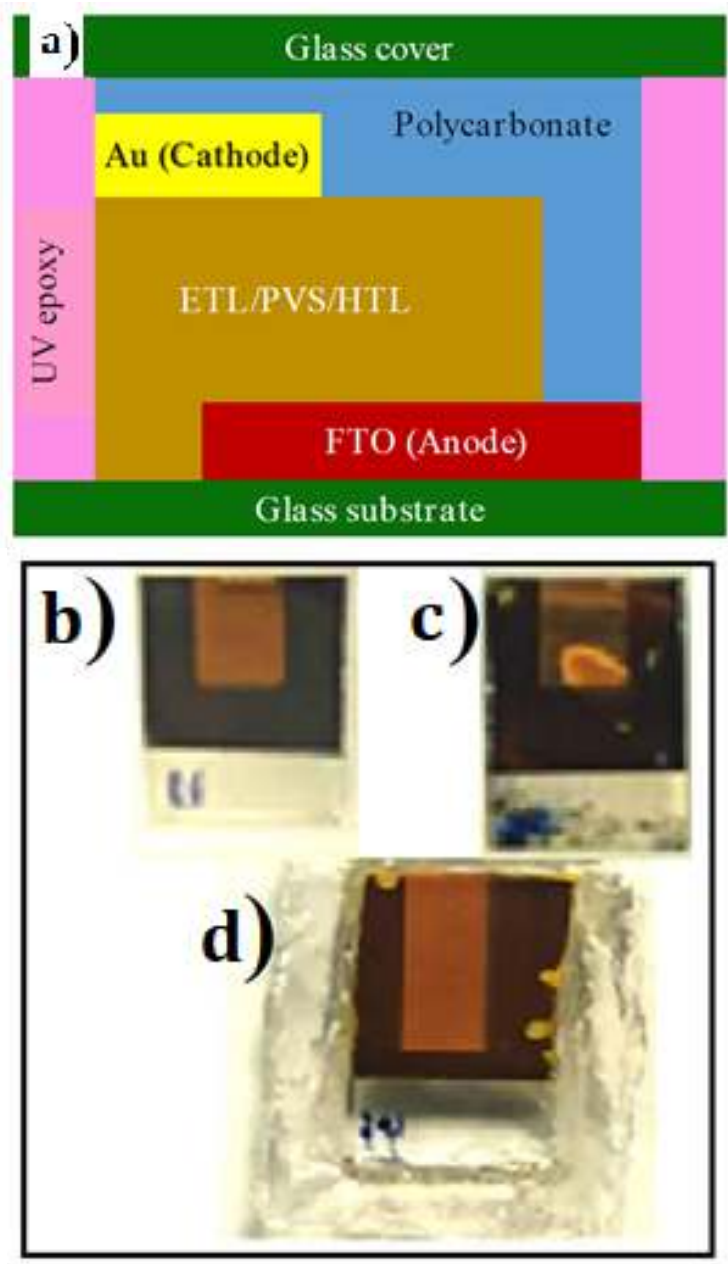

Fig. 5. (a) Schematic view of the structure of a perovskite solar cell encapsulated with polycarbonate and glass polymer and sealed with UV adhesive, (b) capsule-free reference structure, (c) cell encapsulated with clear polycarbonate polymer without glass coating, and (d) final capsule structure with polymer, glass coating, and sealing with adhesive, which after exposure to moisture and heat, keeps a percentage of its stability.

In order to investigate the alterations in current and voltage, as well as the amount of changes in FF and the efficiency of PSCs before and after the capsule, I-V diagrams were drawn for each cell and at each stage after applying the necessary conditions in that stage. First, after making the cell and performing I-V analysis, its diagram was drawn as a reference sample (before the capsule), then the second sample was encapsulated with polycarbonate polymer 
and the current-voltage diagram was examined again. The third sample was exposed to $85 \%$ $\mathrm{RH}$ and $85^{\circ} \mathrm{C}$ for one day, and the next sample was exposed to the above conditions for two days, and the third sample spent three days in the same condition. The parameters of each condition are given separately in Table 1 .

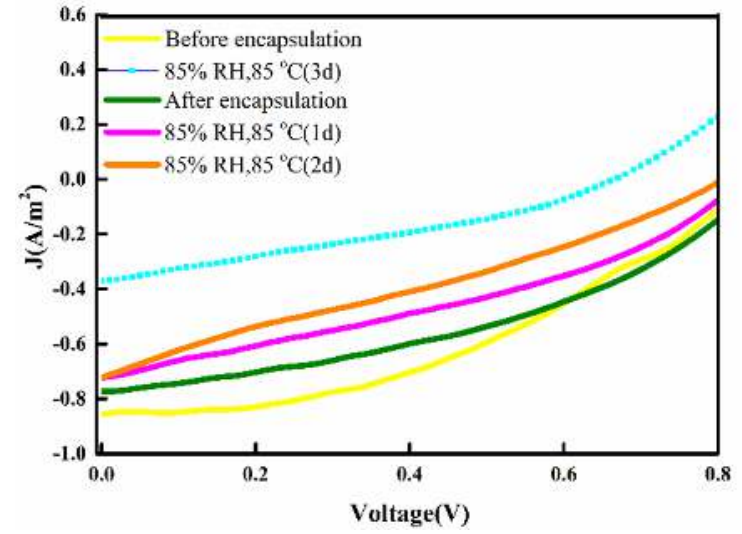

Fig. 6. Density diagram of current-voltage perovskite solar cell before capsule, after capsule, after applying $85 \%$ humidity and $85^{\circ} \mathrm{C}$ temperature on the first, second, and third day.

Table 1 Parameters of PSCs, before and after encapsulation and after application of humidity and heat.

\begin{tabular}{|c|c|c|c|c|c|}
\hline & $\begin{array}{c}\text { Before } \\
\text { encapsulati } \\
\text { on }\end{array}$ & $\begin{array}{c}\text { After } \\
\text { encapsulati } \\
\text { on }\end{array}$ & $\begin{array}{c}\text { First } \\
\text { day }\end{array}$ & $\begin{array}{c}\text { Second } \\
\text { day }\end{array}$ & $\begin{array}{c}\text { Third } \\
\text { day }\end{array}$ \\
\hline $\begin{array}{c}\mathbf{J s c} \\
\left(\mathbf{m A} / \mathbf{m}^{2}\right)\end{array}$ & 10.68 & 10.76 & 10.76 & 5.11 & 4.62 \\
\hline Voc (mV) & 850 & 730 & 730 & 710 & 660 \\
\hline $\mathbf{F F}$ & 40 & 36 & 36 & 26 & 31 \\
\hline PCE (\%) & 3.604 & 2.82 & 2.82 & 0.94 & 0.94 \\
\hline
\end{tabular}

As table above shows, first, before encapsulating the structure, its current-voltage parameters were checked, and after encapsulating the PSCs, the previous steps were followed. To speed up the process of observing the effect of capsule coating on the structure, $85 \% \mathrm{RH}$ and $85^{\circ} \mathrm{C}$ conditions were applied to the structures during consecutive days. The results show that FF first decreases and after the second day increases, and this indicates the positive effect of the capsule layer on the structure. The efficiency of the structure gradually decreases, but compared to the reference cell, i.e. without capsule coating which was completely destroyed after being exposed to the mentioned conditions for 30 minutes and its efficiency reached zero, the performance of the capsule coating is remarkable. The performance degradation of PSCs can occur as a result of thermal instability, sensitivity of the perovskite material to ambient air (humidity and oxygen), and degradation caused by other device components (e.g., degradation at the $\mathrm{TiO} 2$ interface under light exposure and poor stability of the holetransport material). Consequently, the stability of the perovskite thin films and PSCs has been extensively studied, including the degradation of the perovskite material upon exposure to humidity, illumination, or elevated temperature. The increase in fill factor is due to the effects of humidity and temperature. The effect of humidity and temperature on the structure of the perovskite solar cell lengthens the ion migration paths, resulting in an increase in the fill factor.

Before the encapsulation, the current density is 10.68 , and after the encapsulation remeasurement, it changes to 10.76 . This value changed about $0.01 \%$. So we can say that the flow after the capsule has also remained stable. Post-encapsulation stability indicates that the capsule method has no effect on efficiency and a suitable method is used for the capsule structure. One day after encapsulation, the amount of current remained constant and the voltage did not change after overnight exposure of the encapsulated structure to humidity and temperature of $85^{\circ} \mathrm{C}$ and $85 \% \mathrm{RH}$. This indicates the proper functioning of the capsule structure. Because it has a much better performance compared to the reference structure without capsules, which is destroyed in less than 1 hour under the mentioned conditions. On the second and third day, when the capsule structure is still under standard humidity and heat, the current and voltage are somewhat reduced, indicating a slight infiltration of moisture into the structure. However, after several measurements, the capsule structure, despite a slight reduction in efficiency and other basic parameters, is still efficient and has maintained its stability to a high extent under the capsule cover.

The X-ray diffraction (XRD) pattern of the encapsulated, unencapsulated and reference perovskite solar cell are shown in Fig. 7. The 
red diagram is a XRD graph of the reference cell (unencapsulated) prior to the encapsulation of the structure to compare the performance of the polycarbonate capsule coating and the unencapsulated structure. One cell is considered as the reference cell and an unencapsulated structure is placed at $85 \% \mathrm{RH}$, $85^{\circ} \mathrm{C}$ condition.

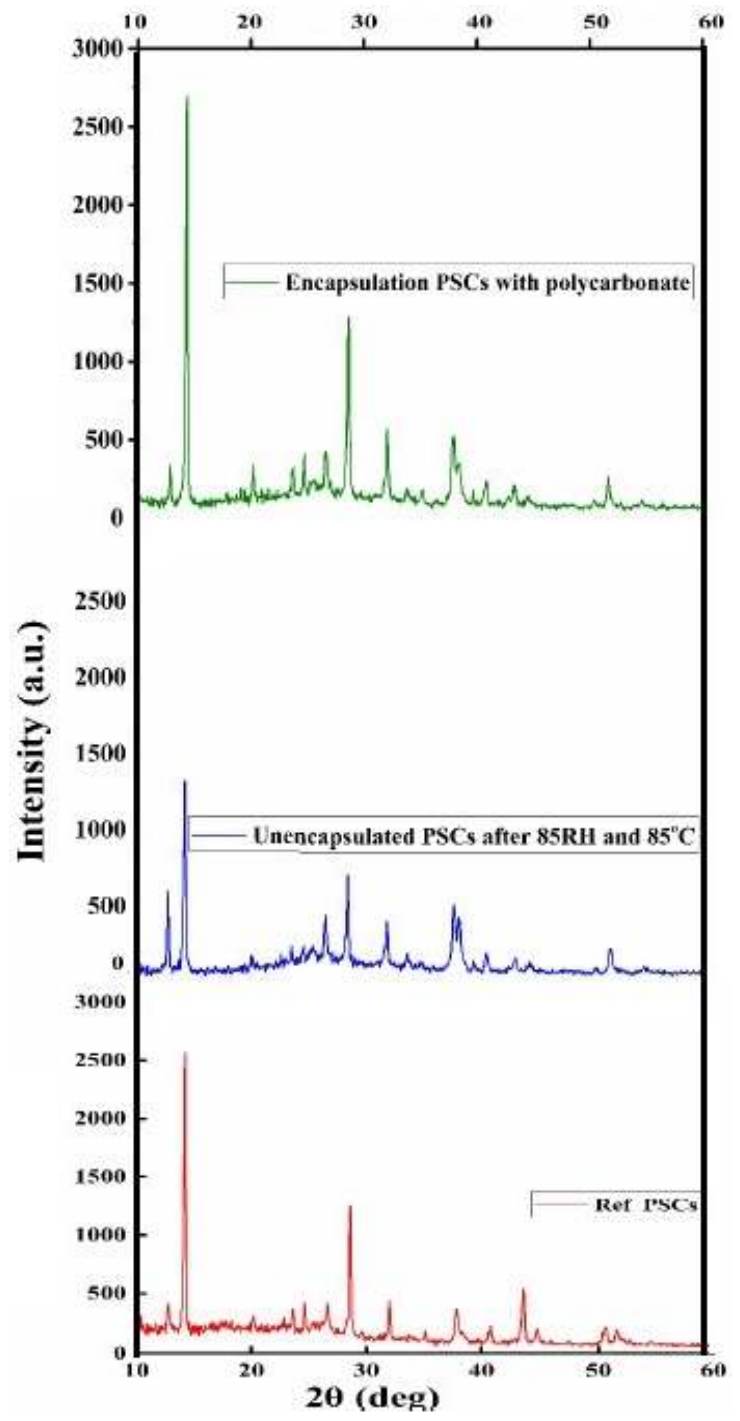

Fig. 7. XRD patterns of the encapsulated, unencapsulated and reference perovskite solar cell.

Another capsulated perovskite solar cell structure which is encapsulated with polycarbonate polymer, placed at the similar condition for the similar period and is compared with the unencapsulated structure relative to the reference cell diagram. The blue diagram is an unencapsulated perovskite solar cell after treatment with humidity and heat. Having compared this graph with the reference cell graph, the destruction of the structure is obvious and it can be explained by the fact that increasing the intensity of $\mathrm{PbI}_{2}$ peak at $2 \theta=12.5^{\circ}$ and decreasing the intensity of perovskite peak at $2 \theta=14.2^{\circ}$ and $28.2^{\circ}$ caused complete destruction of the structure after treatment with moisture and heat. The green diagram is a perovskite solar cell after encapsulation with a thin film of polycarbonate polymer and treatment of humidity and heat. In the XRD pattern, peaks at the angles 14.7, 28.5, and 33.06 correspond respectively to the diffraction of the plates (110), (200) and (210) of the $\mathrm{MAPbI}_{3}$ perovskite structure, which is consistent with other reports. The XRD results clearly indicate that the structure of $\mathrm{MAPbI}_{3}$ was synthesized. The XRD pattern was well matched with the other published articles [2628]. According to the XRD graph of the reference cell and its comparison with that of the structure after the capsule and applying a period of humidity and heat, the lack of the perovskite destruction at peaks of 14.2 and 28.2 and the lack of growth at peak 12.5 are observed which the indicator of $\mathrm{PbI}_{2}$ is. This structure represents more stability than the unencapsulated structure that is placed in similar conditions and degrades rapidly. This indicates the proper performance of the capsule structure on the perovskite solar cell and the protection of the perovskite structure by polycarbonate polymer against humidity and heat.

\section{III.CONCLUSION}

Polymer structures that are resistant to moisture and heat penetration are appropriate candidates for encapsulating and expanding the life scale of solar devices. The capsule layer plays an important role in maintaining the stability of the perovskite solar cell, so that the capsule-free structure is completely destroyed in a short time, but the encapsulated structure shows the stability for a long time. After the studies, it was observed that polycarbonate polymer, due to its heat- and moisture-resistant polymer structure, functions as a suitable capsule structure and protects PSCs. Applying this polymer, in addition to using a glass cap and sealing the 
structure with glue, makes it possible to protect the structure to a considerable extent, and by exposure to the defined conditions, it takes longer period to reaches to $20 \%$ of the initial efficiency.

\section{ACKNOWLEDGMENT}

The research council of the University of Kashan is gratefully acknowledged for the financial support of this study.

\section{REFERENCES}

[1] P. Boland, K. Lee, and G. Namkoong, "Device optimization in PCPDTBT: PCBM plastic solar cells," Solar Energy Materials and Solar Cells, Vol. 94, pp. 915-920, 2010.

[2] C. Liang, Y. Wang, D. Li, X. Ji, F. Zhang, and Z. He, "Modeling and simulation of bulk heterojunction polymer solar cells," Solar energy materials and solar cells, Vol. 127, pp. 67-86, 2014.

[3] F. Jahantigh and M.J. Safikhani, "The effect of HTM on the performance of solid-state dyesanitized solar cells (SDSSCs): a SCAPS-1D simulation study," Appl. Phys. A, Vol. 125, pp. 276 (1-7), 2019.

[4] F. Jahantigh, S.M.B. Ghorashi, and S. Mozaffari, "Orange photoluminescent N-doped graphene quantum dots as an effective cosensitizer for dye-sensitized solar cells," J. Solid State Electrochemistry, Vol. pp. 1-7, 2020 .

[5] F. Jahantigh, S.B. Ghorashi, and A. Bayat, "Hybrid dye sensitized solar cell based on single layer graphene quantum dots, Dyes and Pigments," Vol. 175, pp. 108118, 2020.

[6] P.V. Kamat, "Meeting the clean energy demand: nanostructure architectures for solar energy conversion," J. Phys. Chem. C, Vol. 111,pp. 2834-2860, 2007.

[7] F. Jahantigh, S.B. Ghorashi, and A.R. Belverdi, "A first principle study of benzimidazobenzophenanthrolin and tetraphenyldibenzoperiflanthene to design and construct novel organic solar cells," Physica B: Condensed Matter, Vol. 542, pp. 32-36, 2018.

[8] H. Etesami, M. Mansouri, A. Habibi, and F. Jahantigh, "Synthesis and investigation of double alternating azo group in novel para-azo dyes containing nitro anchoring group for solar cell application," J. Molecular Structure, Vol. 1203, pp. 127432, 2020.

[9] J.-A. Jeong and H.-K. Kim, “ ${ }^{A} l_{2} \mathrm{O}_{3} / \mathrm{Ag} / \mathrm{Al}_{2} \mathrm{O}_{3}$ multilayer thin film passivation prepared by plasma damage-free linear facing target sputtering for organic light emitting diodes," Thin Solid Films, Vol. 547, pp. 63-67, 2013.

[10] J.A. Christians, P.A. Miranda Herrera, and P.V. Kamat, "Transformation of the excited state and photovoltaic efficiency of $\mathrm{CH} 3 \mathrm{NH} 3 \mathrm{PbI} 3$ perovskite upon controlled exposure to humidified air," J. the Amer. Chem. Soc. Vol. 137, pp. 1530-1538, 2015.

[11] J. Yang, B.D. Siempelkamp, D. Liu, and T.L. Kelly, "Investigation of $\mathrm{CH} 3 \mathrm{NH} 3 \mathrm{PbI} 3$ degradation rates and mechanisms in controlled humidity environments using in situ techniques," ACS nano, Vol. 9, pp. 1955-1963, 2015.

[12] J.H. Noh, S.H. Im, J.H. Heo, T.N. Mandal, and S.I. Seok, "Chemical management for colorful, efficient, and stable inorganic-organic hybrid nanostructured solar cells," Nano Lett. Vol. 13, pp. 1764-1769, 2013.

[13] M. Tavakoli, F. Jahantigh, and H. Zarookian, "Adjustable high-power-LED solar simulator with extended spectrum in UV region," Solar Energy, Vo. 220, pp. 1-7, 2020.

[14] H. Tsai, W. Nie, J.-C. Blancon, C.C. Stoumpos, R. Asadpour, B. Harutyunyan, A.J. Neukirch, R. Verduzco, J.J. Crochet, and S. Tretiak, "High-efficiency two-dimensional Ruddlesden-Popper perovskite solar cells," Nature, Vol. 536, pp. 312-316, 2016.

[15] M. Zhang, J.S. Yun, Q. Ma, J. Zheng, C.F.J. Lau, X. Deng, J. Kim, D. Kim, J. Seidel, and M.A. Green, "High-efficiency rubidiumincorporated perovskite solar cells by gas quenching," ACS Energy Lett. Vol. 2, pp. 438444, 2017.

[16]Z. Wei, X. Zheng, H. Chen, X. Long, Z. Wang, and S. Yang, "A multifunctional C+ epoxy/Agpaint cathode enables efficient and stable operation of perovskite solar cells in watery environments," J. Mater. Chem. A, Vol. 3, pp. 16430-16434, 2015.

[17] S.N. Habisreutinger, T. Leijtens, G.E. Eperon, S.D. Stranks, R.J. Nicholas, and H.J. Snaith, "Carbon nanotube/polymer composites as a highly stable hole collection layer in perovskite 
solar cells," Nano Lett. Vol. 14 , pp. 55615568, 2014.

[18]A. Mei, X. Li, L. Liu, Z. Ku, T. Liu, Y. Rong, M. Xu, M. Hu, J. Chen, and Y. Yang, "A holeconductor-free, fully printable mesoscopic perovskite solar cell with high stability," science, Vol. 345, pp. 295-298, 2014.

[19] S. Guarnera, A. Abate, W. Zhang, J.M. Foster, G. Richardson, A. Petrozza, and H.J. Snaith, "Improving the long-term stability of perovskite solar cells with a porous $\mathrm{Al}_{2} \mathrm{O}_{3}$ buffer layer," J. Phys. Chem. Lett. Vol. 6, pp. 432-437, 2015.

[20]D. Yang, Z. Yang, W. Qin, Y. Zhang, S.F. Liu, and C. Li, "Alternating precursor layer deposition for highly stable perovskite films towards efficient solar cells using vacuum deposition," J. Mater. Chem. A, Vol. 3, pp. 9401-9405, 2015.

[21]N. Tripathi, M. Yanagida, Y. Shirai, T. Masuda, L. Han, and K. Miyano, "Hysteresisfree and highly stable perovskite solar cells produced via a chlorine-mediated interdiffusion method," J. Mater. Chem. A, Vol. 3, pp. 12081-12088, 2015.

[22]L. Olson, S. Kundu, M. Gross, and A. Joly, "Damp heat effects on CIGSS and CdTe cells," in: Proc. DOE SETP Review Meeting, Citeseer, pp. 17-19, 2007.

[23]R. Sundaramoorthy, F. Pern, and T. Gessert, "Preliminary damp-heat stability studies of encapsulated CIGS solar cells," in: Reliability of Photovoltaic Cells, Modules, Components, and Systems III, International Society for Optics and Photonics, 2010, pp. 77730Q.

[24]F. Matteocci, L. Cinà, E. Lamanna, S. Cacovich, G. Divitini, P.A. Midgley, C. Ducati, and A. Di Carlo, "Encapsulation for long-term stability enhancement of perovskite solar cells," Nano Energy, Vol. 30, pp.162-172, 2016.

[25]F. Jahantigh and S. Bagher Ghorashi, "Optical simulation and investigation of the effect of hysteresis on the perovskite solar cells," Nano, Vol. 14, pp. 1950127 (1-36), 2019.

[26] T.J. Wilderspin, F. De Rossi, and T.M. Watson, "A simple method to evaluate the effectiveness of encapsulation materials for perovskite solar cells," Solar Energy, Vol. 139, pp. 426-432, 2016.
[27] J. Li, R. Xia, W. Qi, X. Zhou, J. Cheng, Y. Chen, G. Hou, Y. Ding, Y. Li, and Y. Zhao, "Encapsulation of perovskite solar cells for enhanced stability: Structures, materials and characterization," J. Power Sources, Vol. 485, pp. 229313 (1-15), 2021.

[28]B. McKenna, J.R. Troughton, T.M. Watson, and R.C. Evans, "Enhancing the stability of organolead halide perovskite films through polymer encapsulation," RSC Adv. Vol. 7, pp. 32942-32951, 2017.

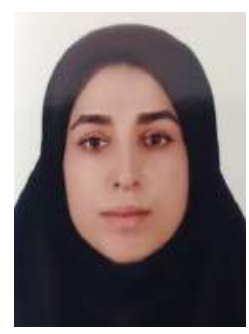

Asieh Nazari Mofrad has received her BSc in plasma engineering physics, master's degree in photonics from Kashan University, Kashan, Iran. Her Master's topic of dissertation is on encapsulation of optoelectronic devices including perovskite solar cells and organic under the supervision of Dr. Ghoreishi, from University of Kashan.

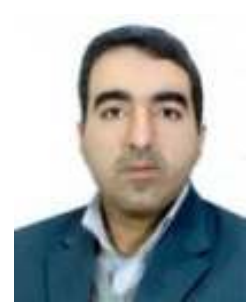

Seyed Mohammad Bagher Ghoreishi received his M.Sc. degree in Atomic and Molecular Physics from Iran University of Esfahan. He is pursuing his study towards Ph.D. in Atomic and Molecular Physics at Yazd University under the supervision of Prof. Behjat. He is an Associate Professor at the University of Kashan. His research interests include optoelectronic devices, dye-sensitized solar cells, provskite solar cells, plasmonics and electrochemical sensors. 


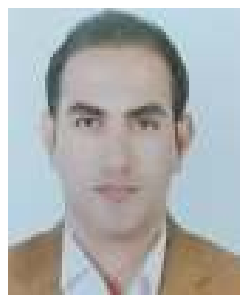

Farhad Jahantigh received his M.Sc. degree in Atomic and Molecular Physics from Iran Tarbiat Modares University. He obtained his Ph.D. in Atomic and Molecular Physics under the supervision of Dr. Ghoreishi, from University of Kashan in 2020. His research focuses on the nanomaterials and solar cell materials. 


\section{THIS PAGE IS INTENTIONALLY LEFT BLANK.}

